\title{
The impact of chronic fatigue syndrome on cognitive functioning in adolescents
}

\author{
Linde N. Nijhof ${ }^{1} \cdot$ Sanne L. Nijhof ${ }^{1} \cdot$ Gijs Bleijenberg $^{2} \cdot$ Rebecca K. Stellato $^{3}$ • \\ Jan L. L. Kimpen ${ }^{1} \cdot$ Hilleke E. Hulshoff Pol ${ }^{4}$ Elise M. van de Putte ${ }^{1}$
}

Received: 18 March 2015 / Revised: 28 June 2015 / Accepted: 17 August 2015 / Published online: 3 September 2015

(C) The Author(s) 2015. This article is published with open access at Springerlink.com

\begin{abstract}
Chronic fatigue syndrome (CFS) is characterized by persistent fatigue and severe disability. Most adolescent patients report attention and concentration problems, with subsequent poor performance at school. This study investigated the impact of CFS on intellectual capacity by (1) assessing discrepancies between current intelligence quotient (IQ) and school level and (2) exploring differences in current IQ and pre-CFS school performance, compared with healthy
\end{abstract}

Communicated by Jaan Toelen

Linde N. Nijhof and Sanne L. Nijhof contributed equally to this work.

Linde N. Nijhof

L.N.Nijhof@umcutrecht.nl

Sanne L. Nijhof

S.L.Nijhof@umcutrecht.nl

Gijs Bleijenberg

Gijs.Bleijenberg@radboudumc.nl

Rebecca K. Stellato

R.K.Stellato@umcutrecht.nl

Jan L. L. Kimpen

J.Kimpen@umcutrecht.nl

Hilleke E. Hulshoff Pol

H.E.Hulshoff@umcutrecht.nl

Elise M. van de Putte

E.vandePutte@umcutrecht.nl

1 Department of Pediatrics, Wilhelmina Children's Hospital, University Medical Centre Utrecht, HP KE.04.133.1, Post box 85090, 3508 AB Utrecht, The Netherlands

2 Expert Center Chronic Fatigue, Radboud University Nijmegen Medical Centre, Nijmegen, The Netherlands

3 Biostatistics, Julius Center for Health Sciences and Primary Care, University Medical Centre Utrecht, Utrecht, The Netherlands

4 Rudolf Magnus Institute of Neuroscience, Department of Psychiatry, University Medical Centre Utrecht, Utrecht, The Netherlands individuals. Current data was cross-sectionally gathered and compared with retrospective pre-CFS school performance data. Fifty-nine CFS adolescents and 40 controls were evaluated on performance on age-appropriate intelligence tests and school level. Current IQ scores of CFS adolescents were lower than expected on the basis of their school level. Furthermore, there was a difference in intelligence performance across time when current IQ scores were compared with preCFS cognitive achievement. Healthy controls did not show any discrepancies.

Conclusion: According to their pre-CFS intelligence assessments, CFS patients started with appropriate secondary school levels at the age of 12. Our data suggest that CFS may be accompanied by a decline in general cognitive functioning. Given the critical age for intellectual development, we recommend a timely diagnosis followed by appropriate treatment of CFS in adolescents.

What is Known:

- Adolescent chronic fatigue syndrome (CFS) is a debilitating condition with major impact on social and intellectual development.

- Most patients report concentration problems, with subsequent poor performance at school. Little is known about the influence of CFS on intellectual performances.

What is New:

- IQ scores of CFS adolescents are lower than the IQ scores of healthy peers with an equivalent school level.

- There is a decrease in intelligence performance across time when current IQ scores are compared with pre-CFS cognitive achievement. Healthy controls do not show any discrepancies between their current IQ, school level and previous cognitive functioning. This suggest that adolescent CFS may be accompanied by a decline in general cognitive functioning.

Keywords Adolescent $\cdot$ School performance $\cdot$ Chronic fatigue syndrome $\cdot$ Cognitive impairment $\cdot$ IQ 


$\begin{array}{ll}\text { Abbreviations } \\ \text { CBT } & \text { Cognitive behavioural therapy } \\ \text { CDC } & \text { Centre for disease control and prevention } \\ \text { CDI } & \text { Children's depression inventory } \\ \text { CIS-20 } & \text { Checklist individual strength } \\ \text { CITO } & \text { Centraal instituut toets ontwikkeling } \\ \text { CFS } & \text { Chronic fatigue syndrome } \\ \text { CHQ-CF87 } & \text { Health questionnaire-child form } \\ \text { HAVO } & \begin{array}{l}\text { Hoger algemeen voortgezet onderwijs } \\ \text { (secondary school of general educational }\end{array} \\ & \text { development) } \\ \text { IQ } & \text { Intelligence quotient } \\ \text { PMTK } & \text { Achievement motivation test for children } \\ \text { SD } & \text { Standard deviation } \\ \text { STAIC } & \text { Spielberger state-trait anxiety inventory for } \\ & \text { children } \\ \text { VMBO } & \text { Voorbereidend middelbaar beroeps onderwijs } \\ & \text { (secondary school of general educational } \\ & \text { development) } \\ \text { VWO } & \text { Voorbereidend wetenschappelijk onderwijs } \\ & \text { (pre-university level) }\end{array}$

\section{Introduction}

Chronic fatigue syndrome (CFS) in adolescents is a disabling condition characterized by severe and unexplained fatigue lasting for more than 6 months, with long-term consequences for educational and social development $[6,20]$. The fatigue is accompanied by additional symptoms such as headaches, myalgia, multiple joint pain, unrefreshing sleep, and memory and concentration problems. Somatic and psychiatric illnesses must be excluded to meet the criteria for CFS [11].

The prevalence of CFS in adolescents has been estimated at between 0.11 and $1.29 \%$ in community studies in the USA and Europe, with a female to male ratio up to 5:1 $[3,10,17,25,29]$.

Both adult and adolescent CFS patients frequently report cognitive problems associated with a perceived change in intellectual abilities [21]. Memory and concentration problems are reported by, respectively, $89 \%$ of adults [16] and $80 \%$ of adolescents [7]. Several studies, mainly focused on adults, have described impaired cognitive performance by CFS patients on neuropsychological tests. These tests measured information-processing speed, memory, motor speed and executive functioning [5]. Reduced speed of complex information processing is the impairment most consistently found $[5,21,22,32]$.

Our clinical observations confirm that CFS adolescents experience a change in cognitive functioning with subsequent poor performance at school. This often leads to a drop in school level during CFS, with subsequent feelings of frustration.
In contrast to memory and concentration problems in CFS patients, the intellectual capacity in adolescents with CFS has rarely been investigated. One study measured the discrepancy between actual and perceived intelligence quotient (IQ) by parents of adolescents with CFS compared to those of parents of healthy peers in a cross-sectional design [12]. Parental expectations of IQ were significantly higher than the actual IQ for children with CFS. The authors concluded that high parental expectations might contribute to the development of CFS and that high expectations may need to be addressed within the context of treatment. However, because of the cross-sectional study design, it remained unclear whether these discrepancies in IQ were causal factors or consequences of CFS.

In this study, we explore the hypothesis that adolescents with CFS show a discrepancy between current IQ and school level irrespective of psychological functioning. Firstly, we compare actual IQ levels of CFS adolescents with those of healthy controls of the same school level. Secondly, we extend the comparison with pre-secondary school IQ levels in both groups. These two comparisons enable us to explore the question if a current difference in IQ level was already apparent in the pre-CFS phase (i.e. pre-secondary school).

\section{Materials and methods}

\section{Design and population}

In this study, current IQ data were cross-sectionally gathered and compared with retrospective standardized school performance assessments at primary school (CITO). This longitudinal design was used to compare intellectual performance in adolescents with CFS and healthy adolescents. Between August 2009 and February 2010, 64 adolescents (12-18 years) participating in the FITNET (Fatigue in Teenagers on the Internet) trial $[23,24]$ were invited to participate in this neurocognitive study when attending their initial assessment at the University Medical Centre Utrecht. Fifty-nine patients agreed to participate $(92 \%)$. All patients met the criteria for chronic fatigue syndrome as defined by the Centers for Disease Control and Prevention (CDC), Atlanta, GA, USA [11]. Exclusion criteria were primary depression, anxiety disorder or suicidal risk [23].

As a reference group, healthy participants from a former control group were re-invited between August 2009 and February 2010 [25]. From this group, adolescents with neurological abnormalities, chronic illnesses or under treatment from a psychiatrist or psychologist were excluded from participation. Forty of 58 eligible healthy adolescents $(69 \%)$ completed ageappropriate intelligence tests. In view of the demographic characteristics and fatigue levels, both the CFS-patients and controls were representative samples of former studies [23, 25]. 


\section{Outcome measures}

(1) Intelligence. All subjects completed age-appropriate short versions of the Wechsler intelligence scales, 3rd edition, Dutch version, to determine intelligence (WISC-III-NL for adolescents until 16 years old and WAIS-III-NL for adolescents of 17 and 18 years old). Full-scale IQ was estimated from four subtests (picture completion, information, block design and vocabulary) $[13,19,30,31]$. Cronbach's alpha for the short version is 0.91 and for the full test 0.95 [13]. IQ was corrected for age and sex.

(2) CITO. Cognitive abilities and educational achievement in primary school were assessed using the Dutch CITO elementary test (Centraal Instituut Toets Ontwikkeling, www.cito.com). The CITO consists of 240 multiplechoice items assessing four different intellectual skills: language, mathematics, information processing and world orientation. Taken together, the performance scales result in a standardized score between 501 and 550. The test is usually administered on three consecutive days in January or February when the children are in the final grade of primary school and approximately 12 years old. This assessment is not a formal IQ test but highly correlates with IQ performance (correlation of 0.63 between CITO and IQ assessed at age 12) [1] and plays an important advisory role in the choice of secondary school education [27]. In the Netherlands, everyone receives comparable primary education from 4 to 12 years of age. Thereafter, depending on general performance and assessment of intellectual capacity measured by the CITO test, a child follows one of four levels of secondary education (VMBO-basis, VMBO-theoretical, HAVO and VWO, corresponding respectively to 'below average', 'average', 'above average' and 'high' levels of attainment). In this study, we have recruited only participants (patients and healthy controls) from the last three categories. The general availability of CITO test scores makes it possible to compare current cross-sectional data with retrospective intelligence data.

Copies of the official CITO reports were collected by email from the adolescents themselves or from teachers after informed consent was obtained. Forty-nine CFS patients and 34 healthy controls $(83 \%$ resp., $85 \%$ response) supplied a copy of their official CITO scores. None of these adolescents had symptoms of CFS at the time of completing the CITO test.

\section{Psychological functioning}

Self-reported questionnaires were used to assess fatigue, concentration problems, anxiety, depression and achievement motivation. Participants were asked to fill out these questionnaires without assistance from their parent(s) or the researcher.

Fatigue and concentration problems were assessed using the self-report questionnaire checklist individual strength (CIS-20), subscales 'fatigue severity' ( 8 items) and 'concentration problems' (5 items). The CIS-20 is a reliable assessment tool with excellent internal consistency (Cronbach's $\alpha$ 0.93) and discriminative validity for CFS [33].

Assessment of trait anxiety in adolescents was performed with a validated Dutch translation of the Spielberger StateTrait Anxiety Inventory for Children (STAIC) [26]. The STAIC consists of 20 statements on a three-point scale.

Depression in adolescents was measured using a validated Dutch translation of the Children's Depression Inventory (CDI) [18]. The CDI quantifies depressive symptoms from the past 2 weeks and consists of 27 items rated on a threepoint scale.

Fear of failure was determined in the adolescents by means of the Achievement Motivation Test for Children (PMTK), a validated Dutch questionnaire that expresses performance pressure, negative fear of failure, positive fear of failure, socially desirable behaviour and combined fear of failure in deciles (1-10) [15].

\section{Ethics}

The medical ethics committee of the University Medical Centre Utrecht approved the study. Written informed consent was obtained from all adolescents and their parent(s), according to the Declaration of Helsinki.

\section{Data analysis}

All variables were tested for normality and if normality was confirmed, parametric statistics were used. Differences between groups were assessed using the independent sample $t$ test and $\chi^{2}$ test. We divided the school educational levels into three groups: level 1 (VMBO-theoretical; average), level 2 (HAVO; above average) and level 3 (VWO; high level).

A two-way ANOVA model was used to explore a possible discrepancy between IQ and school level for CFS patients and healthy controls; the dependent variable was the IQ score and the independent variables were the group (CFS yes/no), the current school level and their interaction.

To examine the effect of CFS on IQ while correcting for potential confounders, linear regression models with CFS (yes/no), age, gender and initial school level were used. Statistical significance was assumed at $p<0.05$. Statistical analyses were performed using IBM SPSS Statistics 20. 


\section{Results}

\section{Descriptive statistics}

The baseline characteristics of the participating adolescents (59 CFS patients and 40 healthy controls) and those who did not want to participate (5 CFS patients and 18 healthy controls) did not differ (data not shown).

Table 1 compares the demographic characteristics and psychological functioning of CFS patients with healthy adolescents. The median duration of CFS inpatients was 20.0 months. Girls predominated both groups, but were significantly overrepresented in the CFS group. Adolescents with CFS reported more fatigue and concentration problems than healthy controls. Also, anxiety and depression levels were higher in the CFS group. There was no difference in achievement motivation.

Table 2 shows school levels and intelligence assessment scores of adolescents with CFS and healthy adolescents. There was no statistically significant difference between CFS patients and the controls regarding initial school level (first-grade secondary school) and current school level (current grade). Notably, 9 of 59 CFS patients (15.3\%) already switched to a lower educational level during the course of the disease. This is in contrast to healthy peers who remained at the same level or switched to a higher $(n=2)$ school level. A decision to switch school level is made in commission by the teachers, parents and the student based on (lack of) academic performance.

Before disease onset, the CFS patients and the healthy peers did not differ in CITO scores. In contrast, current IQ was 8 points lower for CFS patients than for their healthy peers. Performal IQ contributed most to this difference in IQ since patients performed significantly worse on performance IQ than controls, while no significant difference was found for verbal IQ. Table 2 shows adjusted and non-adjusted differences. The model for adjustment was based on Pearson's correlations between IQ and school absence (CFS: $r=0.15, p=0.25$; controls: $r=0.25, p=0.13$ ) and between IQ and psychological adjustment (depression-CDI (CFS: $r=-0.06, p=0.68$; controls: $r=-0.17, p=0.32$ ), anxiety-STAIC (CFS: $r=0.14, p=0.31$; controls: $r=-0.22$, $p=0.19$ ), negative fear of failure (CFS: $r=-0.12, p=0.39$; controls: $r=-0.18, p=0.27)$ ). Because all correlations were weak, and none was statistically significant, we decided to eliminate these potential confounders from the adjusted model. The differences in IQ are only adjusted for age, gender and initial secondary school level in order to ensure that the difference in current intellectual performance is not explained by a confounding variable alone or to some interaction between those variables.

\section{Match between school level and intelligence level (IQ)}

The mean IQ scores per school level for both groups are shown in Table 3. Adolescents with CFS had lower mean IQ scores than the controls at all school levels. The main effect of CFS was significant $(p=0.005)$, as was the main effect of school level $(p=0.001)$. There was no significant interaction between group (CFS yes/no) and school level $(p=0.960)$.

There was an unadjusted difference of nearly 8 points in IQ score, which persisted after adjustment for age, gender and initial school level (mean difference -6.5 ; $95 \% \mathrm{CI}-10.9$ to -2.1) as shown in Table 2. No difference in CITO scores after

Table 1 Demographic features of adolescents with CFS and healthy adolescents

\begin{tabular}{|c|c|c|c|c|}
\hline & $\mathrm{CFS}^{\mathrm{a}} n=59$ & Healthy ${ }^{\mathrm{a}} n=40$ & Mean difference $(95 \% \mathrm{CI})$ & $p$ value \\
\hline \multicolumn{5}{|l|}{ Demographic characteristics } \\
\hline Gender— $\%$ girls & 78 & 55 & - & 0.026 \\
\hline Age at entry-years & $15.8(1.5)$ & $15.7(0.5)$ & $-0.2(-0.6 ; 0.2)$ & 0.394 \\
\hline Duration of CFS symptoms at entry-months ${ }^{\mathfrak{E}}$ & $20.0(17.0)$ & - & - & - \\
\hline School absence- $\%$ & $52.9(33.0)$ & $1.5(2.8)$ & $51.3(42.7 ; 60.0)$ & $<0.001$ \\
\hline \multicolumn{5}{|l|}{ Fatigue assessment } \\
\hline CIS score severity of fatigue (8-56) & $51.5(4.4)$ & $21.2(9.9)$ & $30.3(26.9 ; 33.6)$ & $<0.001$ \\
\hline CIS score concentration problems (5-35) & $29.3(5.6)$ & $16.0(6.2)$ & $13.3(10.9 ; 15.7)$ & $<0.001$ \\
\hline \multicolumn{5}{|l|}{ Psychological adjustment } \\
\hline Anxiety disposition (STAIC; 20 items; 20-60) & $32.3(7.7)$ & $27.9(6.6)$ & $4.3(1.3 ; 7.3)$ & 0.005 \\
\hline Depression disposition (CDI; 27 items; 0-54) & $11.4(5.7)$ & $5.8(4.0)$ & $5.6(3.5 ; 7.6)$ & $<0.001$ \\
\hline \multicolumn{5}{|l|}{ Achievement motivation } \\
\hline PMT-K need to perform & $4.6(2.5)$ & $4.1(2,4)$ & $0.6(-0.4 ; 1.6)$ & 0.268 \\
\hline PMT-K negative fear of failure & $4.4(2.7)$ & $3.9(2.6)$ & $0.5(-0.6 ; 1.6)$ & 0.377 \\
\hline
\end{tabular}

CFS chronic fatigue syndrome, $C I$ confidence interval, CIS checklist individual strength, STAIC State-Trait Anxiety Inventory for Children, $C D I$ Children's Depression Inventory, PMT-K Achievement Motivation Test for Children

${ }^{\text {a }}$ Values are means (SD) unless otherwise stated

${ }^{£}$ Median (IQR) 
Table 2 Intelligence assessment scores of adolescents with CFS and healthy adolescents

\begin{tabular}{|c|c|c|c|c|c|c|}
\hline & $\mathrm{CFS}(\mathrm{SD})^{\mathrm{a}} n=59$ & Healthy (SD) ${ }^{\mathrm{a}} n=40$ & Mean difference $(95 \% \mathrm{CI})$ & $p$ value & Adjusted difference $(95 \% \mathrm{CI})^{\mathrm{b}}$ & $p$ value \\
\hline CITO score $^{\mathrm{c}}(501-550)$ & $540.4(7.0)$ & $541.0(6.6)$ & $-0.6(-3.6 ; 2.4)$ & 0.705 & $-1.0(-3.1 ; 1.1)$ & 0.329 \\
\hline \multicolumn{7}{|l|}{ Initial secondary school level ${ }^{\mathrm{d}}$} \\
\hline Level 1—\% & 28.8 & 22.5 & - & & & \\
\hline Level 2-\% & 28.8 & 35.0 & $\zeta$ & 0.721 & & \\
\hline Level 3-\% & 42.4 & 42.5 & & & & \\
\hline \multicolumn{7}{|c|}{ Current secondary school level } \\
\hline Level $1 — \%$ & 32.2 & 22.5 & - & & & \\
\hline Level 2-\% & 37.3 & 30.0 & $\zeta$ & 0.223 & & \\
\hline Level 3-\% & 30.5 & 47.5 & & & & \\
\hline \multicolumn{7}{|l|}{ Intelligence level } \\
\hline Measured IQ score ${ }^{\mathrm{e}}$ & $103.3(11.4)$ & $111.2(11.0)$ & $-8.0(12.6 ;-3.3)$ & 0.001 & $-6.5(-10.9 ;-2.1)$ & 0.004 \\
\hline \multicolumn{7}{|l|}{ Performance IQ } \\
\hline Block design (1-18) & $10.3(2.5)$ & $11.8(2.2)$ & $1.5(0.6 ; 2.5)$ & 0.002 & $-1.4(-2.4 ;-0.4)$ & 0.006 \\
\hline Picture completion (1-18) & $9.1(2.9)$ & $10.7(2.1)$ & $1.6(0.5 ; 2.7)$ & 0.005 & $-1.3(-2.5 ;-0.1)$ & 0.036 \\
\hline \multicolumn{7}{|l|}{ Verbal IQ } \\
\hline Information (1-19) & $11.0(2.8)$ & $11.7(3.0)$ & $0.7(-0.6 ; 2.0)$ & 0.268 & $-0.3(-1.5 ; 1.0)$ & 0.663 \\
\hline Vocabulary (1-19) & $11.1(2.2)$ & $11.3(2.2)$ & $0.2(-0.8 ; 1.1)$ & 0.728 & $-0.3(-1.2 ; 0.7)$ & 0.572 \\
\hline
\end{tabular}

$C F S$ chronic fatigue syndrome, $C I$ confidence interval, $C I T O$ Centraal Instituut Toets Ontwikkeling, $I Q$ intelligence quotient. IQ: CFS $n=59$, controls $n=$ 39 (1 participant incomplete due to illness)

${ }^{\text {a }}$ Values are means (SD) unless otherwise stated

${ }^{\mathrm{b}}$ Adjusted for age, sex and initial school level

${ }^{\mathrm{c}}$ Intelligence index at the last year of the primary school

dLevel 1, level 2 and level 3 correspond, respectively, to 'average', 'above average' and 'high' levels of attainment

${ }^{\mathrm{e}}$ Estimated IQ measure by subtests

adjustment was found between patients and controls. Also, adjustment for age, gender, initial school level, as well current IQ had no significant effect on estimated CITO test outcomes (mean difference $-1.0 ; 95 \% \mathrm{CI}-3.7$ to 1.8 ).

\section{Discussion}

In our study, we explored pre-CFS and actual intellectual performance in adolescents with CFS compared with healthy peers. We found that current IQ scores of CFS adolescents were lower than the IQ scores of healthy peers with an equivalent school level. Furthermore, there was a diminishing on cognitive functioning across time when current IQ scores were compared with pre-CFS cognitive achievement. Importantly, CITO scores of CFS adolescents corresponded to their initial secondary school level, as was the case with their healthy controls. Healthy controls did not show any discrepancies between their current IQ, school level and previous CITO score.

Table 3 Mean IQ score by school level of adolescents with CFS compared with healthy peers

\begin{tabular}{|c|c|c|c|c|c|c|}
\hline & Educational level $1(\mathrm{VMBO})^{\mathrm{c}}$ & $n$ & 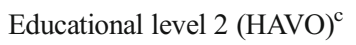 & $n$ & Educational level $3(\mathrm{VWO})^{\mathrm{c}}$ & $n$ \\
\hline \multicolumn{7}{|c|}{ Intelligence quotient $(\mathrm{IQ})^{\mathrm{a}}$} \\
\hline CFS & $96.8(8.6)$ & 19 & $104.8(9.2)$ & 22 & $108.2(13.5)$ & 18 \\
\hline Controls $^{\mathrm{b}}$ & $104.1(14.0)$ & 8 & $110.5(6.9)$ & 12 & $114.7(10.8)$ & 19 \\
\hline
\end{tabular}

There are significant differences between groups at all school levels, $p=0.005$

VMBO Voorbereidend Middelbaar Beroeps Onderwijs, HAVO Hoger Algemeen Voortgezet Onderwijs, VWO Voorbereidend Wetenschappelijk Onderwijs, $C F S$ chronic fatigue syndrome

${ }^{\text {a }}$ Values are means (SD)

${ }^{\mathrm{b}} \mathrm{CFS} n=59$, Controls $n=39$ ( 1 participant incomplete due to illness)

${ }^{\mathrm{c}} \mathrm{VMBO}, \mathrm{HAVO}$ and VWO correspond, respectively, to 'average', 'above average' and 'high' levels of attainment 
The role of IQ in adults and adolescents with CFS has not been well studied. Godfrey et al. studied IQ in CFS adolescents in a cross-sectional study design [12]. Taking into account differences in methodology, our study agrees with Godfrey in that actual IQ in CFS adolescents does not match expectations, which in our study were based on their present school level and pre-CFS school performance. Godfrey et al. showed that parents' expectations regarding the IQ of adolescents with CFS were significantly higher than those of healthy controls. They concluded that the high expectations of parents could contribute to the development of CFS. However, pre-CFS IQ levels of CFS adolescents in our study were equal to that of healthy peers, suggesting that the actual lower IQ levels in CFS adolescents represent a consequence rather than a cause of CFS. This could imply that the parents in the study of Godfrey et al. had realistic expectations about their children's intellectual potential but that IQ was affected during the course of the disease.

Many explanations for the lower actual IQ can be postulated. CFS is often accompanied by considerable school absence. The discrepancy between IQ and school level could be explained by the high level of school absence, which leads to reduced knowledge. However, an IQ test should be independent of school attendance, and in this study, we observed no correlation between IQ and school absence in neither the CFS nor in the control group. We therefore postulate that IQ is affected in CFS adolescents independently of absence from school. Also, no correlations between IQ and fear of failure, anxiety or depression were found. These findings are in accordance with the results of Cockshell et al. (2010), who undertook a meta-analysis on the cognitive performance of adults ( $>16)$ with CFS compared with healthy controls. Problems in neuropsychological functioning were found to be unrelated to depression, fatigue or anxiety [5]. Thus, neither school absence nor psychological functioning seems to be an adequate explanation for our findings.

Secondly, a (subjective) neurocognitive impairment is inherent in CFS adolescents and might influence the IQ score. Previous studies, mostly in adults, showed a diminished performance in information-processing speed and in tasks requiring working memory over a sustained period of time $[4,5,21,22$, 32]. In addition, a study specifically in CFS adolescents noted cognitive problems among attention and memory abilities [14]. This could imply that CFS adolescents achieve a lowered IQ score on subtests that require fast processing. The fact that performance intelligence is particularly diminished in our study would fit this premise. If this assumption is true, IQ scores should normalize after treatment of and recovery from CFS.

Thirdly, CFS may affect brain development and thereby cognitive development in adolescence and thus have a possible relationship with a reduced IQ since adolescence is a critical phase of brain development [28]. There are functional magnetic studies (fMRI) that show that activation of the lateral prefrontal cortex is common for a range of intelligence tests and that the magnitude of frontal cortical activation correlates highly with intelligence [2, 31]. Remarkably, MRI studies in CFS patients of de Lange et al. detected lower cortical grey matter volume in adult CFS compared with healthy controls, with a significant increase in grey matter volume in CFS patients, localized in the lateral prefrontal cortex after effective treatment with CBT $[8$, 9]. This change in cerebral volume was also related to improvements in cognitive speed in the CFS patients. De Lange et al. (2008) conclude that cortical plasticity in the adult human brain is responsible for the change in cerebral volume, demonstrating a surprisingly dynamic relation between behavioural state and cerebral anatomy. Given this possibility, CFS may affect brain development in adolescence and thus have a possible causal relationship with a reduced IQ.

An alternative explanation could be that adolescent CFS patients 'grow into the deficit'. Although the CITO test highly correlates with IQ scores assessed at the age of 12 [1], it is not a formal IQ test. The CFS adolescents in our study underperformed in particular in the performance tasks, while no significant difference was found for verbal IQ between CFS and healthy adolescents. We cannot exclude a pre-existent difference in performance and verbal IQ (which may not be measured with a CITO test), representing a vulnerability factor, partly responsible for the development of CFS in adolescents.

Some issues need further consideration. We used CITO scores as a pre-CFS proxy of IQ-scores, while the CITO test is not a formal IQ test. However, it highly correlates with IQ scores assessed at the age of 12 [1]. Moreover, the unique setting in the Netherlands, with a general availability of CITO test scores, makes it possible to compare current cross-sectional data with retrospectively collected pre-CFS intelligence data.

The controls were comparable to patients in terms of age and school level, but not for gender. We adjusted for these differences in our analysis.

A strong aspect of our study is the longitudinal design; by assessing pre-CFS intellectual performance, we have two time points, enabling to compare intellectual performance in CFS adolescents and healthy controls in time. Another strength of our study was the high participation rate: $92 \%$ of the eligible CFS patients entered the study, thus reducing the risk of bias. Accurately diagnosing CFS is complex and requires exclusion of other illnesses that could cause similar complaints, but require different treatment. In the FITNET study, CFS was strictly diagnosed using the CDC criteria, in a tertiary academic hospital setting. Since referrals were obtained nationwide and from various sources (general practitioners as well as paediatricians), we consider our study population representative of the Dutch CFS population at large [23]. The control group was recruited for a number of sub-studies of the FITNET study, thus not specifically for a neurocognitive assessment or intelligence test, also reducing the risk of selection bias. In addition, the demographic data indicate that both groups are similar in terms of mean school level and in mean CITO scores before the onset of CFS. 
In conclusion, adolescent CFS may be accompanied by a decline in general cognitive functioning. Regardless of the etiological role of intelligence in the emergence of CFS, we advise caution in interpreting intellectual performance tests measured during the course of the disease. It is currently not known whether lower IQ outcomes are due to concentration problems, a lowered processing speed or CFS itself. Given the critical age for intellectual development, we recommend a timely diagnosis followed by appropriate treatment of CFS in adolescents.

\begin{abstract}
Authors' Contributions LNN was the primary investigator and, together with SLN, responsible for data gathering and analysis and drafting the report. EMVDP, GB and JLLK designed and supervised the study. HEHP revised the manuscript critically. EMVDP was responsible for diagnosis of the chronic fatigue syndrome in adolescents. LNN, SLN and RKS did the data analysis. All authors have read and approved the final report.
\end{abstract}

Ethical standards The medical ethics committee of the University Medical Centre Utrecht approved the study. Written informed consent was obtained from all adolescents and their parent(s), according to the Declaration of Helsinki.

Conflict of interest The authors declare that they have no competing interests.

Statement of financial support This work was partially supported by the Netherlands Organization for Health Research and Development, ID ZonMW 60-60800-98-013.

Role of the funding source The sponsor of the study had no role in study design, data gathering, data analysis and data interpretation or writing the report. The corresponding author had full access to all the data in the study and had final responsibility for the decision to submit for publication.

Open Access This article is distributed under the terms of the Creative Commons Attribution 4.0 International License (http:// creativecommons.org/licenses/by/4.0/), which permits unrestricted use, distribution, and reproduction in any medium, provided you give appropriate credit to the original author(s) and the source, provide a link to the Creative Commons license, and indicate if changes were made.

\section{References}

1. Bartels M, Rietveld MJ, Van Baal GC, Boomsma DI (2002) Heritability of educational achievement in 12-year-olds and the overlap with cognitive ability. Twin Res. doi:10.1375/ 136905202762342017

2. Brans RG, Kahn RS, Schnack HG, van Baal GC, Posthuma D, van Haren NE, Lepage C, Lerch JP, Collins DL, Evans AC, Boomsma DI, Hulshoff Pol HE (2010) Brain plasticity and intellectual ability are influenced by shared genes. J Neurosci. doi:10.1523/ JNEUROSCI.5841-09.2010

3. Chalder T, Goodman R, Wessely S, Hotopf M, Meltzer H (2003) Epidemiology of chronic fatigue syndrome and self reported myalgic encephalomyelitis in 5-15 year olds: cross sectional study. BMJ 327:654-655
4. Cho HJ, Skowera A, Cleare A, Wessely S (2006) Chronic fatigue syndrome: an update focusing on phenomenology and pathophysiology. Curr Opin Psychiatry. doi:10.1097/01.yco.0000194370. 40062.b0

5. Cockshell SJ, Mathias JL (2010) Cognitive functioning in chronic fatigue syndrome: a meta-analysis. Psychol Med 40(8):1253-1267

6. Crawley E, Sterne JA (2009) Association between school absence and physical function in paediatric chronic fatigue syndrome/myalgic encephalopathy. Arch Dis Child. doi:10. 1136/adc.2008.143537

7. Davies S, Crawley E (2008) Chronic fatigue syndrome in children aged 11 years old and younger. Arch Dis Child. doi:10.1136/adc. 2007.126649

8. de Lange FP, Koers A, Kalkman JS, Bleijenberg G, Hagoort P, van der Meer JW, Toni I (2008) Increase in prefrontal cortical volume following cognitive behavioural therapy in patients with chronic fatigue syndrome. Brain. doi:10.1093/brain/awn140

9. De Lange FP, Kalkman JS, Bleijenberg G, Hagoort P, Van Der Meer JWM, Toni I (2005) Gray matter volume reduction in the chronic fatigue syndrome. Neuroimage 26(3):777-781

10. Farmer A, Fowler T, Scourfield J, Thapar A (2004) Prevalence of chronic disabling fatigue in children and adolescents. Br J Psychiatry 184:477-481

11. Fukuda K, Straus SE, Hickie I, Sharpe MC, Dobbins JG, Komaroff A (1994) The chronic fatigue syndrome: a comprehensive approach to its definition and study. International Chronic Fatigue Syndrome Study Group. Ann Intern Med 121:953-959

12. Godfrey E, Cleare A, Coddington A, Roberts A, Weinman J, Chalder T (2009) Chronic fatigue syndrome in adolescents: do parental expectations of their child's intellectual ability match the child's ability? J Psychosom Res 67(2):165-168

13. Gregoire J (2000) Comparison of three short forms of the Wechsler intelligence scale for children - third edition (WISCIII). European Review of Applied Psychology/Revue Europeenne de Psychologie Appliquee

14. Haig-Ferguson A, Tucker P, Eaton N, Hunt L, Crawley E (2009) Memory and attention problems in children with chronic fatigue syndrome or myalgic encephalopathy. Arch Dis Child

15. Hermans HJ (1970) A questionnaire measure of achievement motivation. J Appl Psychol 54(4):353-363

16. Jason LA, Richman JA, Rademaker AW, Jordan KM, Plioplys AV, Taylor RR, McCready W, Huang CF, Plioplys S (1999) A community-based study of chronic fatigue syndrome. Arch Intern Med 159(18):2129-2137

17. Jones JF, Nisenbaum R, Solomon L, Reyes M, Reeves WC (2004) Chronic fatigue syndrome and other fatiguing illnesses in adolescents: a population-based study. J Adolesc Health 35(1):34-40

18. Kovacs M (1985) The Children's Depression Inventory (CDI). Psychopharmacol Bull 21(4):995-998

19. Kulas JF, Axelrod BN (2002) Comparison of seven-subtest and Satz-Mogel short forms of the WAIS-III. J Clin Psychol. doi:10. 1002/jclp.2009

20. Marshall GS (1999) Report of a workshop on the epidemiology, natural history, and pathogenesis of chronic fatigue syndrome in adolescents. J Pediatr 134:395

21. Michiels V, Cluydts R (2001) Neuropsychological functioning in chronic fatigue syndrome: a review. Acta Psychiatr Scand 103(2): 84-93

22. Moss-Morris R, Petrie KJ, Large RG, Kydd RR (1996) Neuropsychological deficits in chronic fatigue syndrome: artifact or reality? J Neurol Neurosurg Psychiatry

23. Nijhof SL, Bleijenberg G, Uiterwaal CS, Kimpen JL, van de Putte EM (2012) Effectiveness of internet-based cognitive behavioural treatment for adolescents with chronic fatigue syndrome (FITNET): a randomised controlled trial. Lancet. doi:10.1016/ S0140-6736(12)60025-7 
24. Nijhof SL, Bleijenberg G, Uiterwaal CS, Kimpen JL, van de Putte EM (2011) Fatigue In Teenagers on the interNET-the FITNET Trial. A randomized clinical trial of web-based cognitive behavioural therapy for adolescents with chronic fatigue syndrome: study protocol. [ISRCTN59878666]. BMC Neurol. doi:10.1186/14712377-11-23

25. Nijhof SL, Maijer K, Bleijenberg G, Uiterwaal CS, Kimpen JL, van de Putte EM (2011) Adolescent chronic fatigue syndrome: prevalence, incidence, and morbidity. Pediatrics. doi:10.1542/peds.2010-1147

26. Papay JP, Spielberger CD (1986) Assessment of anxiety and achievement in kindergarten and first- and second-grade children. Journal of Abnormal Child Psychology: An official publication of the International Society for Research in Child and Adolescent Psychopathology 14(2):279-286

27. Polderman TJ, Bartels M, Verhulst FC, Huizink AC, van Beijsterveldt CE, Boomsma DI (2010) No effect of classroom sharing on educational achievement in twins: a prospective, longitudinal cohort study. J Epidemiol Community Health. doi:10.1136/ jech.2009.091629

28. Ramsden S, Richardson FM, Josse G, Thomas MS, Ellis C, Shakeshaft C, Seghier ML, Price CJ (2011) Verbal and non- verbal intelligence changes in the teenage brain. Nature. doi:10. 1038/nature10514

29. Rimes KA, Goodman R, Hotopf M, Wessely S, Meltzer H, Chalder $\mathrm{T}$ (2007) Incidence, prognosis, and risk factors for fatigue and chronic fatigue syndrome in adolescents: a prospective community study. Pediatrics 119(3):e603-9

30. Schrimsher GW, O'Bryant SE, O'Jile JR, Sutker PB (2008) Comparison of tetradic WAIS-III short forms in predicting full scale IQ scores in neuropsychiatric clinic settings. J Psychopathol Behav Assess

31. Shaw P, Greenstein D, Lerch J, Clasen L, Lenroot R, Gogtay N, Evans A, Rapoport J, Giedd J (2006) Intellectual ability and cortical development in children and adolescents. Nature 440(7084):676-679

32. Tiersky LA, Johnson SK, Lange G, Natelson BH, DeLuca J (1997) Neuropsychology of chronic fatigue syndrome: a critical review. J Clin Exp Neuropsychol 19(4):560-586

33. Vercoulen JH, Swanink CM, Fennis JF, Galama JM, van der Meer JW, Bleijenberg G (1994) Dimensional assessment of chronic fatigue syndrome. J Psychosom Res 38:383-392 